\title{
Assessment and Evaluation of Band Ratios, Brovey and HSV Techniques for Lithologic Discrimination and Mapping Using Landsat ETM ${ }^{+}$and SPOT-5 Data
}

\author{
Ahmed Madani, ${ }^{1,2}$ \\ ${ }^{1}$ Water Research Center, King Abdul Aziz University, Jeddah, KSA \\ ${ }^{2}$ Geology Department, Faculty of Science, Cairo University, Giza, Egypt \\ Email: aamadani18@hotmail.com
}

Received June 24, 2013; revised July 23, 2013; accepted August 21, 2013

Copyright (C) 2014 Ahmed Madani. This is an open access article distributed under the Creative Commons Attribution License, which permits unrestricted use, distribution, and reproduction in any medium, provided the original work is properly cited. In accordance of the Creative Commons Attribution License all Copyrights (C) 2014 are reserved for SCIRP and the owner of the intellectual property Ahmed Madani. All Copyright (C) 2014 are guarded by law and by SCIRP as a guardian.

\section{ABSTRACT}

This study aims to assess and to evaluate band ratios, brovey and HSV (Hue-Saturation-Value) techniques for discrimination and mapping the basement rock units exposed at Wadi Bulghah area, Saudi Arabia using multispectral Landsat ETM ${ }^{+}$and SPOT-5 panchromatic data. FieldSpec instrument is utilized to collect the spectral data of diorite, marble, gossan and volcanics, the main rock units exposed at the study area. Spectral profile of diorite exhibits very distinguished absorption features around $2.20 \mu \mathrm{m}$ and $2.35 \mu \mathrm{m}$ wavelength regions. These absorption features lead to lowering the band ratio values within the band-7 wavelength region. Diorite intrusions appear to have grey and dark grey image signatures on $7 / 3$ and $7 / 2$ band ratio images respectively. On the false color composite ratio image (7/3:R; 7/2:G and 5/2:B), diorite, marble, gossan and volcanics have very dark brown, dark blue, white and yellowish brown image signatures respectively. Image fusion between previously mentioned FCC ratio image and high spatial resolution (5 meters) SPOT-5 panchromatic image is carried out by using brovey and HSV transformation methods. Visual and statistical assessment methods prove that HSV fused image yields best image interpretability results rather than brovey image. It improves the spatial resolution of the original FCC ratios image with acceptable spectral preservation.

\section{KEYWORDS}

\section{Landsat ETM+ Data; SPOT-5 Panchromatic Image; Band Ratios-Brovey and HSV Techniques}

\section{Introduction}

The Neoproterozoic Arabian Shield is composed of five distinct terranes separated by four ophiolite-bearing suture zones: three ensimatic island arc terranes in the western part of the shield (Asir, Hijaz and Midyan) and Afif and Ar Rayn terranes of continental affinity further to the east [1-3]. Wadi Bulghah area is located at the western part of the Afif terrane to the east of the Nabitah suture zone, approximately $520 \mathrm{~km}$ west-northwest of Riyadh city, the capital of Saudi Arabia. Figure 1 shows 3D perspective view of Landsat false color composite (FCC) image (bands 7, 4 \& 2; RGB) draped over Shuttle Radar Topography Mission (SRTM) digital elevation model. It shows the four main different rock units ex- posed at the study area; diorite, marble, gossan and Hulayfah volcanics. Hulayfah volcanics, the oldest rock units exposed at the study area, are made up of the older Afna Formation and the younger Nuqrah Formation, intruded by syn- to late-tectonic diorite intrusions. Andesitic volcanic rocks and volcaniclastic derivatives commonly occur in the western and eastern part of the area and may represent rocks of Afna formation. Nuqrah formation is mostly represented by acidic volcaniclastic rocks including agglomerate, fine laminated tuffs and intercalations of jasper or cherty tuffs. Discontinuous small lenses of gossans are mostly exposed at the western part of the study area. Discontinuous marble bands forming nearly N-S to NNW trending ridges were exposed in the central part of the study area to the east of 


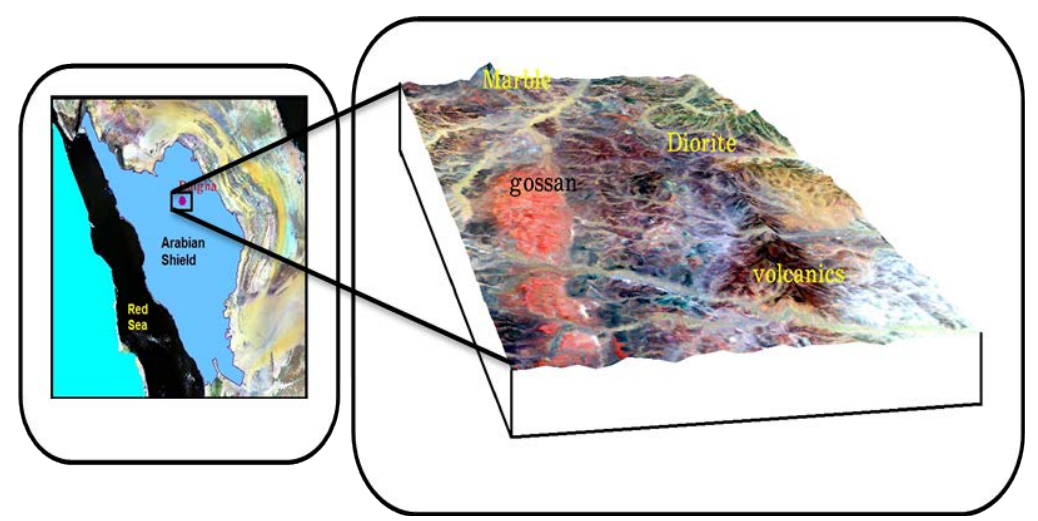

Figure 1. 3D perspective view of Landsat false color composite (FCC) image (bands 7, 4 \& 2; RGB) draped over Shuttle Radar Topography Mission (SRTM) digital elevation model shows the different rock units exposed at the study area.

diorite intrusions. The study area hosts mainly syn- to late tectonic gold-bearing diorite intrusions. Gold deposits at Bulghah area are considered to be mesothermal gold deposits, a major type of gold mineralization in the Arabian Shield, and particularly abundant in the western part of the Afif terrane [4].

Reference [5] studied in detail the spectral characteristics of the mineralized diorite intrusions exposed at Bulghah mine area, Saudi Arabia, using FieldSpec spectroradiometer and Landsat ETM+ data. They categorized the diorite intrusions at the study area into (group A; low general reflectance values) and (group B; high reflectance values with three main absorption features around $1.45 \mu \mathrm{m}, 2.20 \mu \mathrm{m}$ and $2.35 \mu \mathrm{m}$ wavelength regions).

Band ratio and image fusion are the most important techniques used for lithologic discrimination and geological mapping. Band ratio can be simply generated by dividing the reflectance value of each pixel in one band by the reflectance value of the same pixel in another band [6]. Image fusion technique is a process of combining multi-spectral and panchromatic images to produce a new scene which has the best of original images. Image fusion algorithms can be categorized into low (pixel-level), mid (feature-level) and high (symbolic) level. Many algorithms are developed to fuse high spectral resolution image with the high spatial resolution panchromatic image such as brovey, IHS (Intensity-Hue-Saturation), PCA (Principal-Component-Analyses), HSV (HueSaturation-Value) and Wavelet transform. Merging information from different imaging sensors involves two distinct steps [7]. First, the digital images from different sensors are geometrically registered to one another. Next, the information content spatial and spectral is mixed to generate a single image that contains the best of both sets. The merging of the three multispectral bands with another image channel is carried out by intensity substitution [8].

The present study aims to: 1) understand the spectral characteristics of diorite, gossan, marble and volcanics, the main rock units exposed at the study area, using
FieldSpec measurements and apply the acquired knowledge for rock discrimination using band ratio technique; 2) assess the accuracy of brovey and HSV image fusion techniques for mapping purposes visually and statistically.

\section{Materials and Methods}

Table 1; shows the technical characteristics of Landsat $\mathrm{ETM}^{+}$and SPOT-5 data used throughout this study. Landsat $\mathrm{ETM}^{+}$scene has eight broad spectral bands. Six of these bands detect visible, Near Infrared (NIR) and Short Wave Infrared (SWIR) radiations $(0.45 \mu \mathrm{m}$ to 2.35 $\mu \mathrm{m})$ with 30 meters spatial resolution. Band seven detects thermal radiation with 60 meters spatial resolution whereas band eight has 15 meters spatial resolution. The six non-thermal landsat bands are used to generate band ratio images. SPOT 5 was launched on May 4, 2002 and has two high resolution geometrical (HRG) instruments. SPOT-5 records data in two different modes, low-resolution multispectral mode $(10 \mathrm{~m}$ and $20 \mathrm{~m})$ and highresolution panchromatic mode (2.5 to $5 \mathrm{~m}$ ). High spatial resolution SPOT-5 panchromatic band $(5 \mathrm{~m})$ is used in the present study for merging process.

\subsection{Spectral Characteristics of Rocks}

Throughout the present study, FieldSpec spectroradiometer instrument is used to collect the spectral data for diorite, marble, gossan and volcanic rock samples. The FieldSpec instrument is specifically designed for field environment to acquire visible near-infrared (VNIR) and shortwave infrared (SWIR) spectra [9]. In the present study, the spectral data collection took place under suitable weather conditions (sunny, cloud-free day). Data measurements should be resampled as "RTRTRTRT" format in which " $\mathrm{R}$ " refers to reference spectra on a white panel whereas "T" refers to the measured rock sample. Figure 2 shows the compiled FieldSpec profiles for diorite, marble, gossan and volcanics. Three main 
Table 1. Landsat ETM ${ }^{+}$and SPOT-5 panchromatic band technical characteristics.

\begin{tabular}{|c|c|c|c|}
\hline Sensor/Satellite & Electromagnetic Spectrum & Pixel Size & Spectral Bands \\
\hline Landsat $\mathrm{ETM}^{+}$ & Multi-spectral & $30 \mathrm{~m}$ & $\begin{array}{l}\text { Band } 1(0.45-0.52 \mu \mathrm{m}) \\
\text { Band } 2(0.52-0.60 \mu \mathrm{m}) \\
\text { Band } 3(0.63-0.69 \mu \mathrm{m}) \\
\text { Band } 4(0.76-0.90 \mu \mathrm{m}) \\
\text { Band } 5(1.55-1.75 \mu \mathrm{m}) \\
\text { Band } 7(2.08-2.35 \mu \mathrm{m})\end{array}$ \\
\hline SPOT-5 & Panchromatic & $5 \mathrm{~m}$ & $0.48-0.71 \mu \mathrm{m}$ \\
\hline
\end{tabular}

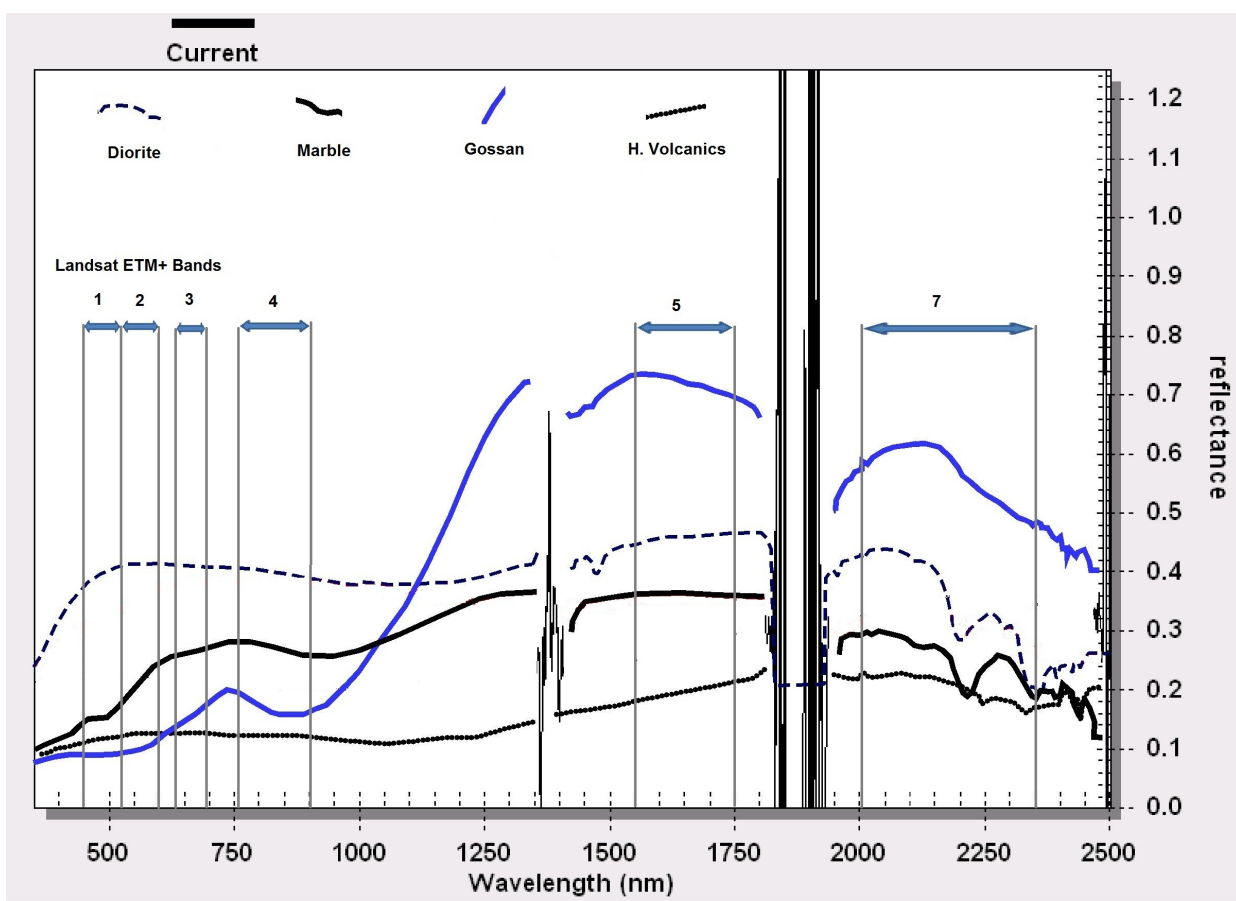

Figure 2. Compiled spectral profiles for diorite, marble, gossan and Hulayfah volcanics collected using FieldSpec instrument.

absorption features around 1.45, 2.20 and $2.35 \mu \mathrm{m}$ wavelength regions are characterized the spectral of profile of diorite intrusion with high reflectance values ( 40\%). Marble FieldSpec spectral profile shows an open absorption feature around $0.90 \mu \mathrm{m}$ wavelength region in addition to, broad absorption feature near $2.2 \mu \mathrm{m}$ wavelength region. The spectral profile of gossan is characterized by increased reflectance values from $10 \%$ in VNIR to $70 \%$ around band 5 wavelength region. It shows small open absorption feature near $0.85 \mu \mathrm{m}$. The FieldSpec spectral profile of Hulayfah volcanics shows general low reflectance values throughout the VNIR and SWIR wavelength regions with two small absorption features around 2.25 $\mu \mathrm{m}$ and $2.35 \mu \mathrm{m}$ wavelength regions.

\subsection{Landsat Image Processing}

Before performing band ratio technique, Landsat $\mathrm{ETM}^{+}$ reflectance calculations are carried out. The aim of $\mathrm{ETM}^{+}$ data reflectance calculations is to convert the $\mathrm{DN}$ values of Landsat $\mathrm{ETM}^{+}$image subset to reflectance data used later to perform band ratios technique $[10,11]$.

\section{Band Ratio Technique}

In the present study, non-thermal Landsat $\mathrm{ETM}^{+}$bands are used to generate the ratio images using ENVI v.4.5 software. Visual inspection of the generated band ratio images revealed that $7 / 3,7 / 2$ and $5 / 2$ band ratio images are the most informative ratios for rock discrimination at the study area. Table 2; shows the reflectance and band ratios values for diorite, marble, gossan and volcanics calculated based on FieldSpec measurements. The bright image signatures of gossan on 5/2, 7/2 and 7/3 (Figures 3(a)-(c)) are attributed to high ratios values 7.4, 4.8 \& 3.2 respectively. Diorite and volcanics have low ratios values and they appear to have grey and dark grey image signatures on the above mentioned ratio images. The information contained in the above three band ratio images are integrated into one false color composite ratio image (7/3:R; 7/2:G and 5/2:B; Figure 3(d)). This FCC ratios image discriminates easily gossan, diorite, volcanics 
Table 2. Reflectance and band ratios values of different rock units calculated based on FieldSpec measurements.

\begin{tabular}{|c|c|c|c|c|c|c|c|}
\hline \multirow{2}{*}{ Rock unit } & \multicolumn{4}{|c|}{ Refl. \% (based on FieldSpec data) } & \multirow{2}{*}{ Ratio 7/3 } & \multirow{2}{*}{ Ratio 7/2 } & \multirow{2}{*}{ Ratio 5/2 } \\
\hline & Band 2 & Band 3 & Band 5 & Band 7 & & & \\
\hline Gossan & 0.10 & 0.15 & 0.74 & 0.48 & 3.2 & 4.8 & 7.4 \\
\hline Marble & 0.23 & 0.26 & 0.36 & $0.18(\mathrm{AF})$ & 0.692 & 0.782 & 1.56 \\
\hline Diorite & 0.41 & 0.41 & 0.46 & $0.28(\mathrm{AF})$ & 0.682 & 0.628 & 1.12 \\
\hline Volcanics & 0.12 & 0.12 & 0.20 & $0.16(\mathrm{AF})$ & 1.33 & 1.33 & 1.66 \\
\hline
\end{tabular}

AF: Values at absorption features.
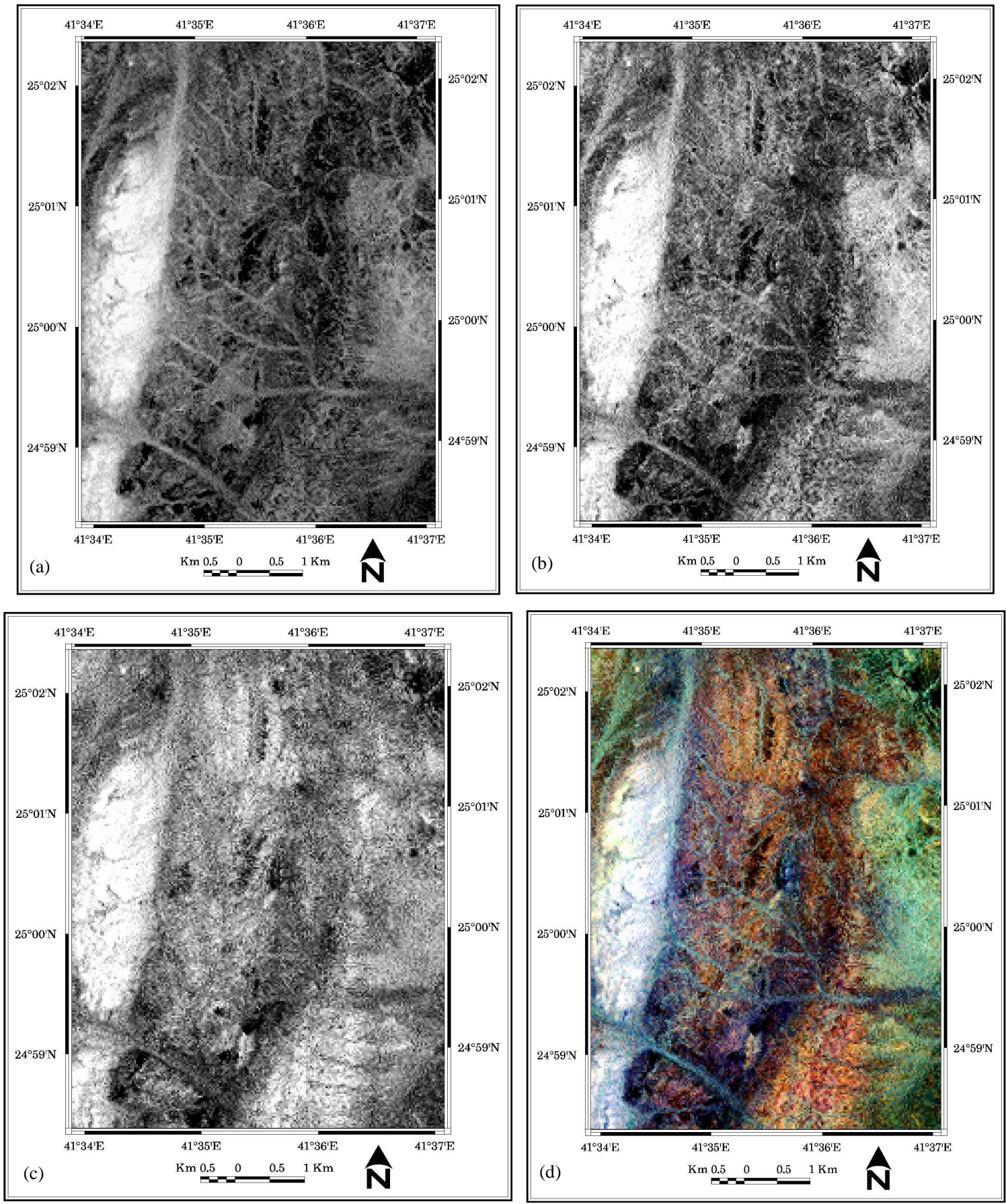

Figure 3. (a) 5/2 band ratio image; (b) 7/2 band ratio image; (c) 7/3 band ratio image and (d) False color composite band ratios image $7 / 3,7 / 2 \& 5 / 2$ in RGB respectively covering the study area. 
and marble by white, very dark brown, yellowish brown and dark blue image signatures, respectively.

\subsection{Image Fusion Techniques}

Image fusion is the process of combining information from two or more images into a single composite image that is more informative and is more suitable for visual interpretation [12]. The fused images can provide information that sometimes cannot be observed in the individual input images. In the present study false color composite Landsat ratios image (7/3, R; 7/2, G \& 5/2, B) is fused with the high spatial resolution (5 meters) SPOT panchromatic image using Brovey and HSV transformation methods. Results of the two fusion transformation methods are assessed statistically to select the most interpretable fused image used for geological mapping. The Brovey transform is the simplest fusion technique in which the grey levels (GL) values for each band are divided by the sum of all the color layers (Red, Green and Blue) and then multiply by the intensity layer (SPOT-5 panchromatic image). The HSV color fusion system is closely related to IHS fusion method, in which " $H$ " is hue, "S" is saturation and " $V$ " is value. During the fusion process the component " $\mathrm{V}$ " is substituted by a high spatial resolution SPOT-5 panchromatic image. Reference [13] merged a false color composite ratio image (5/7, 3/1 \& 4/5) with the panchromatic high spatial resolution scanned aerial photograph using Hue, Saturation, Value (HSV) merger to produce 1:20,000 geological map for the hydrothermal alteration zones along the Haimur gold mine area, south Eastern Desert, Egypt. The merging process was performed in three steps: 1) transformation of the multispectral ratios image from RGB to HSV space; 2) substitution of the intensity value from the high spatial resolution SPOT-5 panchromatic band and 3) back transformation to RGB.

\section{Fusion Results and Assessment}

Several authors dealt with the assessment and evaluation of fusion techniques; [14-16]. Figures 4(a) and (b) show the results of brovey and HSV fused images respectively. Visual and statistical assessment methods are used to ensure the improvement of spatial resolution and preservation of spectral characteristics of the original band ratios false color composite image.

Visual inspection of the brovey fused image revealed the following: 1) the majority of the fused image has low spatial resolution except the gossan ridges at the western side of the study area; 2) no preservation of the spectral characteristics of the original FCC ratios image. These observations are confirmed statistically using correlation coefficient values (CC) (Table 3). The correlation coefficient (CC) measures the correlation between the original and the fused images. The ideal CC value is 1. Table 3 shows the values of the correlation coefficient for brovey image are range between 0.035564 and -0.130294 (Figure 5) which indicates large loss of spectral characteristics of original ratios image during brovey transfor-
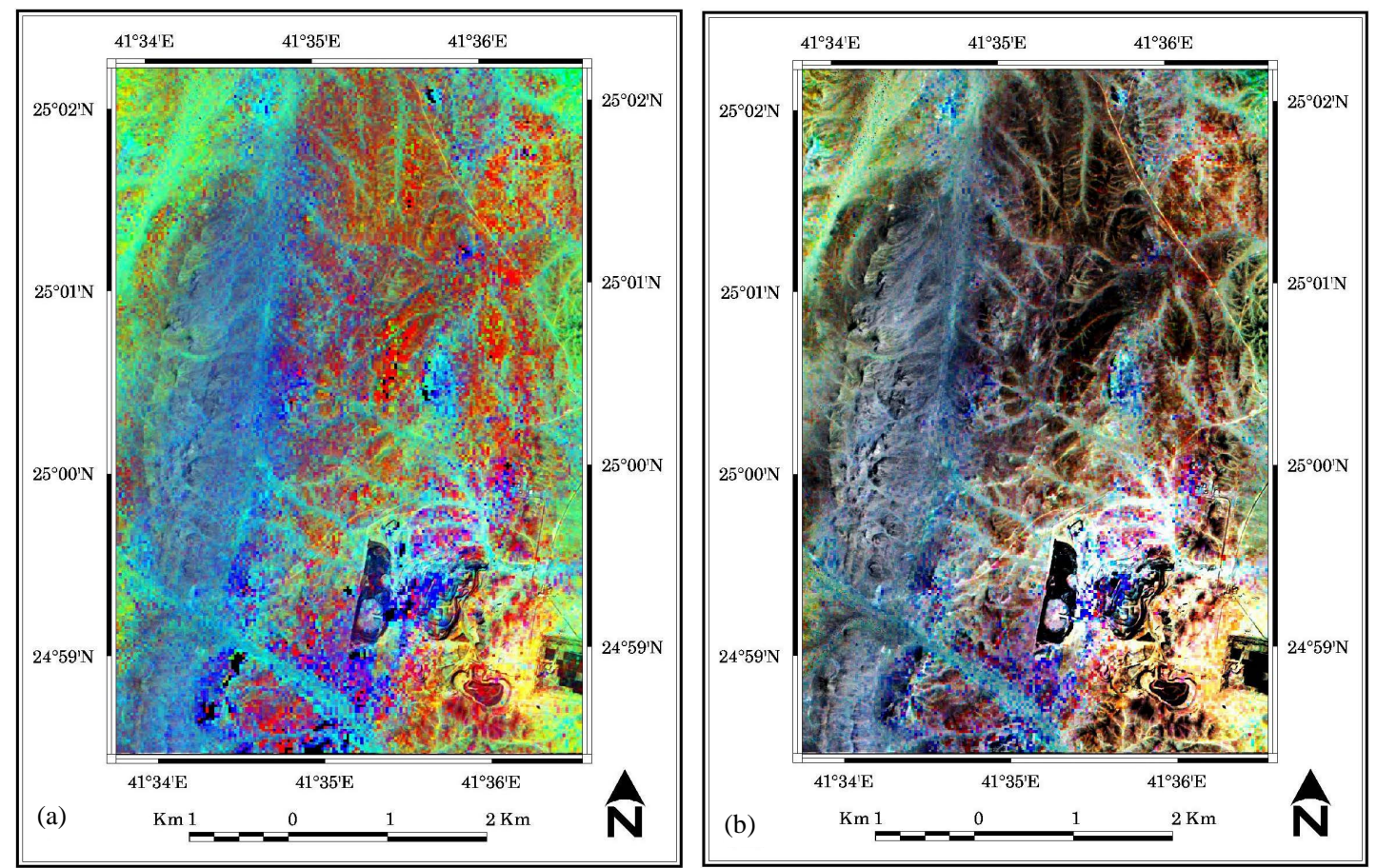

Figure 4. (a) Brovey fused image displayed in the band combination: red, green \& blue. (b) HSV fused image for the study area displayed in the band combination: red, green $\&$ blue. 
International Journal of Geosciences, 2014, 5, 5-11

Published Online January 2014 (http://www.scirp.org/journal/ijg) http://dx.doi.org/10.4236/ijg.2014.51002

Table 3. Statistical characteristics of the fused images.

\begin{tabular}{ccccc}
\hline $\begin{array}{c}\text { Fusion } \\
\text { Method }\end{array}$ & Mean & St.dev. & Eigenvalue \\
\hline \multirow{2}{*}{ Brovey } & 38.783292 & 13.525529 & 280.107921 \\
& 34.940075 & 8.487679 & 75.304632 \\
& 30.324068 & 12.623910 & 58.931181 \\
HSV & 86.404401 & 47.404949 & 4641.729352 \\
& 81.793209 & 44.233003 & 1041.042568 \\
Fusion & 71.131851 & 42.075900 & 291.397247 \\
\hline Method & \multicolumn{5}{c}{ Correlation Coefficient (CC) } \\
\hline \multirow{3}{*}{ HSV } & Correlation & Band 1 & Band 2 & Band 3 \\
& Band 1 & 1.000000 & $\mathbf{0 . 7 3 7 9 4 9}$ & 0.481477 \\
& Band 2 & 0.737949 & 1.000000 & 0.766351 \\
& Band 3 & $\mathbf{0 . 4 8 1 4 7 7}$ & $\mathbf{0 . 7 6 6 3 5 1}$ & 1.000000 \\
& Correlation & Band 1 & Band 2 & Band 3 \\
& Band 1 & 1.000000 & $-\mathbf{0 . 1 3 0 2 9 4}$ & -0.629071 \\
Brovey & Band 2 & -0.130294 & 1.000000 & $\mathbf{0 . 0 3 5 5 6 4}$ \\
& Band 3 & $-\mathbf{0 . 6 2 9 0 7 1}$ & 0.035564 & 1.000000 \\
\hline
\end{tabular}

mation.

Visual inspection of HSV fused image revealed the following: 1) HSV improved the spatial resolution and maintain it all over the entire image. 2) Improvement of the spatial resolution of marble ridges. They appear to have deep blue color trending in N-S direction. 3) There is some loss of the spectral characteristics of rock units e.g. gossan ridges have white image signature on the original FCC band ratios image and grey image signature on HSV fused image. 4) Diorite and volcanics still maintain their original color. Also these observations are confirmed statistically by (CC) values (Table 3 ). The values of the correlation coefficient are ranges between 0.481477 and 0.766351 (Figure 5) which indicates a moderate correlation to the original data. Figure 5 shows the correlation coefficient between the original ratio image and brovey and HSV fused images. HSV fused image shows the high correlation coefficient compared to brovey fused image. It gives best results for interpretability than brovey image (Table 4). It preserves for large extent the spectral characteristics of the original FCC ratios image.

\section{Conclusion}

This study proved the usefulness of band ratios and HSV fusion technique for lithologic discrimination and map- ping the different basement rock units exposed at Wadi Bulghah area, Saudi Arabia. FieldSpec profiles are utilized to understand the spectral characteristics of diorite, Table 4. Image interpretability of Brovey and HSV fused images.

\begin{tabular}{ccccc}
\hline \multirow{2}{*}{ Rock Units } & \multicolumn{2}{c}{ Brovey } & \multicolumn{2}{c}{ HSV } \\
\cline { 2 - 5 } & $\begin{array}{c}\text { Spatial } \\
\text { Improvement }\end{array}$ & $\begin{array}{c}\text { Spectral } \\
\text { Preservation }\end{array}$ & $\begin{array}{c}\text { Spatial } \\
\text { Improvement }\end{array}$ & $\begin{array}{c}\text { Spectral } \\
\text { Preservation }\end{array}$ \\
\hline Diorite & $\mathrm{X}$ & $\mathrm{X}$ & good & good \\
Volcanics & $\mathrm{X}$ & $\mathrm{X}$ & good & good \\
Marble & $\mathrm{X}$ & $\mathrm{X}$ & good & good \\
Gossan & good & $\mathrm{X}$ & good & $\mathrm{X}$ \\
\hline
\end{tabular}

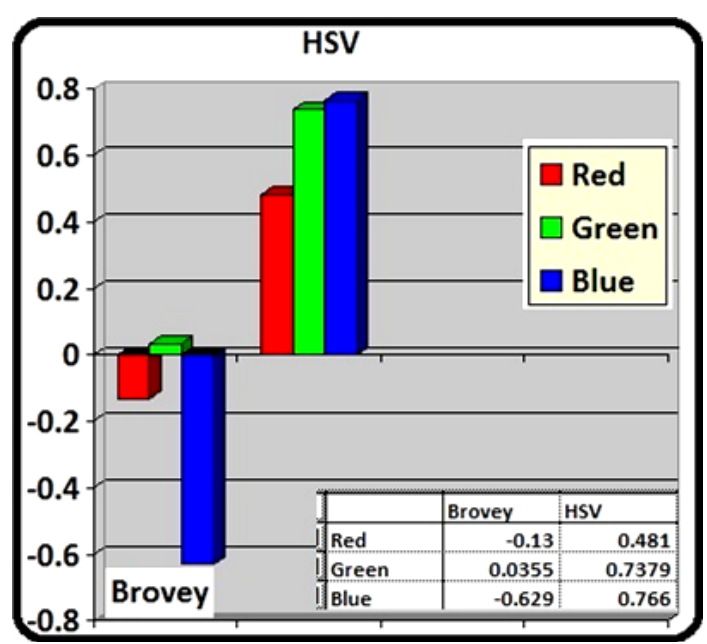

Figure 5. Correlation Coefficient of brovey and HSV fused images.

gossan, marble and volcanics and to select the optimum band ratios used for lithologics discrimination. Image fusion between FCC ratio image (7/3, R; 7/2, G \& 5/2, B) and high spatial resolution (5 meters) SPOT-5 panchromatic image is carried out by using Brovey and HSV transformation methods. Visual and statistical assessment of fusion methods revealed that HSV fused image gave best interpretability results. It improved spatial resolution and maintained at large extent the spectral preservation of the original FCC ratio image.

\section{REFERENCES}

[1] A. M. Al Shanti and A. H. Mitchell, "Late Precambrian Subduction and Collision in the Al Amar-Idsas Region, Arabian Shield, Kingdom of Saudi Arabia,” Tectonophysics, Vol. 30, 3-4, 1976, pp. 41-47.

[2] A. R. Bakor, I. G. Gass and C. Neary, "Jabal Al Wask, Northwest Saudi Arabia, an Eocambrian Back-Arc Ophiolite,” Earth and Planetary Science Letters, Vol. 30, 1, 
1976, pp. 1-9.

http://dx.doi.org/10.1016/0012-821X(76)90002-9

[3] V. E. Camp, "Island-Arcs and Their Role in the Evolution of the Western Arabian Shield," Geological Society of America Bulletin, Vol. 95, 8, 1984, pp. 913-921. http://dx.doi.org/10.1130/0016-7606(1984)95<913:IAAT $\underline{\mathrm{RI}>2.0 . \mathrm{CO} ; 2}$

[4] A. C. Barnicoat, S. R. Freeman, I. H. Henderson and G. M. Phillips, "Structural Controls on Gold Mineralization in the Bulgah Prospect,” Rock Deformation ResearchLeeds University, Report 03, 1989, p. 101.

[5] A. Madani and H. Harbi, "Spectroscopy of the Mineralized Tonalite-Diorite Intrusions, Bulghah Gold Mine Area, Saudi Arabia: Effects of Opaques and Alteration Products on Fieldspec Data," Ore Geology Reviews, Vol. 44, 2012, pp. 148-157. http://dx.doi.org/10.1016/j.oregeorev.2011.09.013

[6] S. Drury, "Image Interpretation in Geology," 2nd Edition, Chapman and Hall, London, 1993.

[7] P. S. Chavez and J. Bowell, "Comparison of the Spectral Information Content of Landsat Thematic Mapper and SPOT for Three Different Sites in the Phoenix, Arizona Region," Photogrammetric Engineering \& Remote Sensing, Vol. 54, No. 12, 1988, pp. 1699-1708.

[8] V. K. Schettigara, “A Generalized Component Substitution Technique for Spatial Enhancement of Multispectral Mages Using Higher Resolution Data," Photogrammetric Engineering \& Remote Sensing, Vol. 58, No. 5, 1992, pp. 561-567.

[9] ASD, “FieldSpec ${ }^{\circledR} 3$ User Manual,” ASD Inc., Boulder,
2007.

[10] P. Curran, "Principles of Remote Sensing," Longman Scientific \& Technical, Harlow, 1985.

[11] W. G. Rees, "Physical Principles of Remote Sensing," Cambridge University Press, Cambridge, 1990.

[12] A. Pohl and L. Van Genderen, "Review Article Multisensory Image Fusion in Remote Sensing: Concepts, Methods and Applications," International Journal or Remote Sensing, Vol. 19, No. 5, 1998, pp. 823-854. http://dx.doi.org/10.1080/014311698215748

[13] A. Madani, E. Abdel Rahman, K. Fawzy and A. Emam, "Mapping of the Hydrothermal Alteration Zones at Haimur Gold Mine Area, South Eastern Desert, Egypt Using Remote Sensing Techniques," The Egyptian Journal of Remote Sensing \& Space Sciences, Vol. 6, 2003, pp. 4760.

[14] E. Marcelino, A. Formaggio and E. Maeda, "Landslide Inventory Using Image Fusion Techniques in Brazil,” International Journal of Applied Earth Observation and Geoinformation, Vol. 11, 3, 2009, pp. 181-191.

[15] S. Klonus and M. Ehlers, "Performance of Evaluation Methods in Image Fusion," 12th International Conference on Information Fusion, Seattle, 6-9 July 2009, pp. 1409-1416.

[16] M. Yakhdani, and A. Azizi, "Quality Assessment of Image Fusion Techniques for Multisensory High Resolution Satellite Images (Case Study: IRS-P5 and IRS-P6 Satellite Images),” ISPRS TC VII Symposium, Vol. 39, 2010, pp. 204-209. 